\title{
Status of ASME Section III Task Group on Graphite Core Support Structures
}

\author{
Robert L. Bratton
}

August 2005

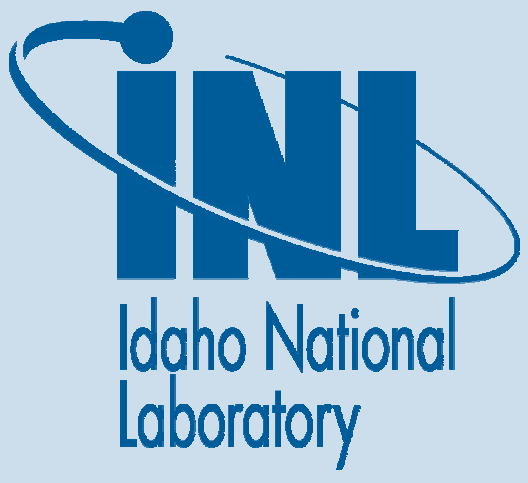

The INL is a U.S. Department of Energy National Laboratory operated by Battelle Energy Alliance 


\title{
Status of ASME Section III Task Group on Graphite Core Support Structures
}

\author{
Robert L. Bratton \\ August 2005 \\ Idaho National Laboratory \\ Department of Nuclear Materials Disposition and Engineering \\ Idaho Falls, Idaho 83415 \\ Prepared for the \\ U.S. Department of Energy \\ Office of Nuclear Energy, Science, and Technology \\ Under DOE-NE Idaho Operations Office \\ Contract DE-AC07-05ID14517
}




\section{Status of ASME Section III Task Group on Graphite Core Support Structures}

INL/EXT-05-00552

August 2005

Approved by
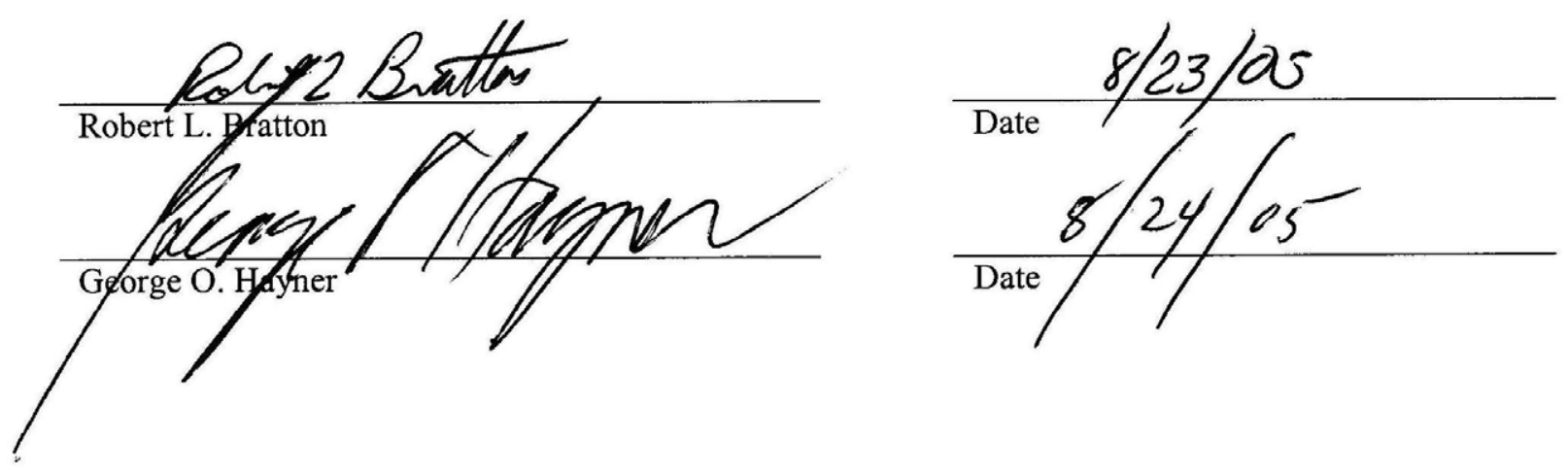


\section{ABSTRACT}

This report outlines the roadmap that the ASME Project Team on Graphite Core Supports is pursuing to establish design codes for unirradiated and irradiated graphite core components during its first year of operation. It discusses the deficiencies in the proposed Section III, Division 2, Subsection CE graphite design code and the different approaches the Project Team has taken to address those deficiencies. 



\section{SUMMARY}

The genesis of the American Society of Mechanical Engineers (ASME) Graphite Project Team on Core Supports resulted from a workshop at Oak Ridge National Laboratory (ORNL) on October 15-16, 2003. The Nuclear Regulatory Commission (NRC) contracted ONRL to hold the ASME Graphite Code Workshop to seek out all potential stakeholders to gauge their level of interest and recruit members of the code committee. The meeting was attended by representatives from graphite manufactures, gas reactor vendors, and U.S. Department of Energy (DOE) national laboratories to build a consensus on how to restart the previous ASME effort of developing an ASME nuclear graphite design code standard. In 1990, the Section III, Division 2, Subsection CE "Design Requirements for Graphite Core Supports," was submitted to the Section III Board for review and comment. Since 1990, there has been no activity on the code nor has the code committee been active. The NRC staff identified a lack of American Society for Testing and Materials (ASTM) material specifications and ASME design codes for graphite core support structures from discussions with Exelon on their proposed licensing approach for the pebble bed reactor. As a result of the workshop and discussion between ORNL and ASME, the first meeting of the committee was held in February 2004.

The current charter for the project team is as follows:

"The committee shall establish codes, standards and guides for materials selection and qualification, design, fabrication, testing, installation, examination, inspection, certification, and the preparation of reports for manufacture and installation of nonmetallic internal components for graphite-moderated fission reactors, where nonmetallic internal components are defined as components, including control rods and assemblies, contained within a graphite-moderated fission reactor pressure vessel and manufactured from graphite, carbon, carbon/carbon composites, ceramics, or ceramic matrix composites. The codes, standards, and guides shall apply to nonmetallic components as defined above. The codes, standards, and guides shall not apply to graphite fuel matrix materials, fuel compacts, fuel pebbles, bushings, bearings, seals, blanket materials, instrumentation, or components internal to the reactor other than those defined above."

Subsection CE was structured in a similar manner as a metallic design code. Subsection CE did not have the required databases for material properties and performance qualification for graphite as metallic design codes have. The ASTM nuclear graphite specification undergoing final balloting will establish a minimum material specification, but it is not an absolute specification. Graphite is manufactured by several different methods and uses different mined and manmade precursors. Therefore, nuclear graphite will have minimum specifications, but maximums will vary from grade to grade and billet to billet. Metallic databases deal with unirradiated properties of the material, while graphite properties will change with absorbed dose and temperature of irradiation. There will be no ASTM specification on the irradiated properties because the effects will vary among the different grades of graphite. Graphite is a brittle material with statistical variability in material properties (i.e., graphite strength). Therefore, statistical consideration of graphite strength is required to develop probabilistically based stress criteria. 



\section{CONTENTS}

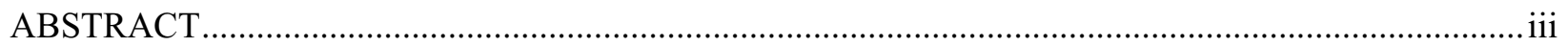

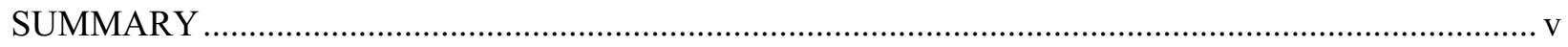

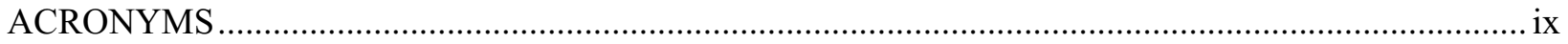

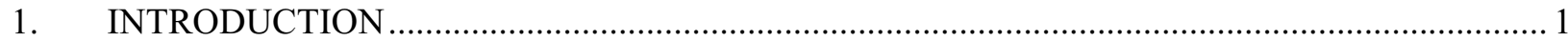

2. PROJECT TEAM ON GRAPHITE CORE COMPONENTS CHARTER …............................... 1

3. ISSUES WITH THE 1990 DRAFT OF SUBSECTION CE ...................................................... 2

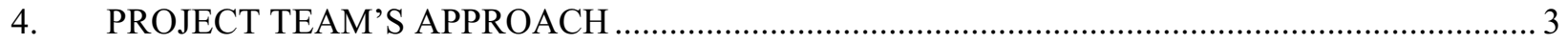

Appendix A Working Draft of the ASME Graphite Design Code ….................................................... 6

\section{FIGURES}

1. Design flowsheet for unirradiated and irradiated graphite …........................................................ 5

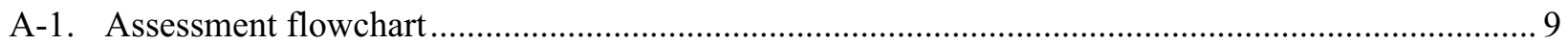

\section{TABLES}

A-1. Summary of the methods selected for design ...... .14 



\section{ACRONYMS}

ASME American Society of Mechanical Engineers

ASTM American Society for Testing and Materials

BPV Boiler and Pressure Vessel

DOE U.S. Department of Energy

KTA Kerntechnische Ausschuss, the German ASME equivalent

NASA National Aeronautics and Space Administration

NRC Nuclear Regulatory Commission

VHTR Very High Temperature Reactor 


\section{Status of ASME Section III Task Group on Graphite Core Support Structures}

\section{INTRODUCTION}

The genesis of the American Society of Mechanical Engineers (ASME) Graphite Project Team on Core Supports resulted from a workshop at Oak Ridge National Laboratory (ORNL) on October 15-16, 2003. The Nuclear Regulatory Commission (NRC) contracted ONRL to hold the ASME Graphite Code Workshop to seek out all potential stakeholders to gauge their level of interest and recruit members of the code committee. The meeting was attended by representatives from graphite manufactures, gas reactor vendors, and U.S. Department of Energy (DOE) national laboratories to build a consensus on how to restart the previous ASME effort of developing an ASME nuclear graphite design code standard. In 1990, the Section III, Division 2, Subsection CE "Design Requirements for Graphite Core Supports," was submitted to the Section III Board for review and comment. Since 1990, there has been no activity on the code nor has the code committee been active. The NRC staff identified a lack of American Society for Testing and Materials (ASTM) material specifications and ASME design codes for graphite core support structures from discussions with Exelon on their proposed licensing approach for the pebble bed reactor. As a result of the workshop and discussion between ORNL and ASME, the first meeting of the committee was held in February 2004.

Later in 2004, Exelon decided not to pursue the pebble bed reactor, and the NRC discontinued sending a representative to committee meetings. However, there was support from the reactor vendors, Generation IV Forum members, and DOE national laboratories. At the same time, DOE was pursuing the Next Generation Nuclear Plant project for which the leading reactor candidate was the Very High Temperature Reactor (VHTR). The VHTR concept has three reactor candidates: (1) an advanced hightemperature prismatic reactor, (2) the advanced pebble bed reactor, and (3) the molten salt reactor. All three concepts employ graphite cores and thus the requirement of an ASME graphite design code to support the design of the graphite cores. The participation in the committee has grown and now includes South African National Nuclear Regulator and the National Aeronautics and Space Administration (NASA). Unfortunately General Atomics has chosen not to participate, but the NRC has reconsidered their position and will be sending a representative in the future due to the impending PBMR Ltd. license application.

Currently the committee's official title is the Section III Project Team on Graphite Core Components. The permanent home for the committee is a matter being discussed in the ASME Executive Board. The project team sent a letter to the ASME Executive Board requesting assignment to the Section III of the ASME Boiler and Pressure Vessel (BPV) Code. The other option was for the ASME Executive Board to reserve a new section in the ASME BPV Code for the graphite design codes. The project team members feel the code will address irradiated graphite behavior, and thus a permanent home in Section III will add more creditability to the code.

\section{PROJECT TEAM ON GRAPHITE CORE COMPONENTS CHARTER}

The current charter for the project team is as follows:

The committee shall establish codes, standards and guides for materials selection and qualification, design, fabrication, testing, installation, examination, inspection, certification, and the preparation of reports for manufacture and installation of nonmetallic internal components for graphite-moderated fission 
reactors, where nonmetallic internal components are defined as components, including control rods and assemblies, contained within a graphite-moderated fission reactor pressure vessel and manufactured from graphite, carbon, carbon/carbon composites, ceramics, or ceramic matrix composites. The codes, standards, and guides shall apply to nonmetallic components as defined above. The codes, standards, and guides shall not apply to graphite fuel matrix materials, fuel compacts, fuel pebbles, bushings, bearings, seals, blanket materials, instrumentation, or components internal to the reactor other than those defined above.

The project team feels graphite design codes are of higher importance than design codes for carbon/carbon composite and ceramics materials. The carbon/carbon composites and ceramic materials are not yet mature to the point where ASTM standards can be developed. Without ASTM standards, the actual material being considered does not have the pedigree to be recognized by the ASME Board. ASTM standards for graphite are undergoing final balloting or round robin testing at this time. A departure from the prior drafted code is that the charter includes the graphite used in prismatic fuel blocks, but not the graphite matrix containing the fuel. The project team feels the graphite used in the prismatic fuel blocks should be included in the design codes responsibility contrary to prior drafted Subsection CE, which excluded the graphite in the fuel blocks.

\section{ISSUES WITH THE 1990 DRAFT OF SUBSECTION CE}

Subsection CE was structured in a similar manner as a metallic design code. Subsection CE did not have the required databases for material properties and performance qualification for graphite as metallic design codes have. The ASTM nuclear graphite specification undergoing final balloting will establish a minimum material specification, but it is not an absolute specification. Graphite is manufactured by several different methods and uses different mined and man-made precursors. Therefore, nuclear graphite will have minimum specifications, but maximums will vary from grade to grade and billet to billet. Metallic databases deal with unirradiated properties of the material, while graphite properties will change with absorbed dose and temperature of irradiation. There will be no ASTM specification on the irradiated properties because the effects will vary among the different grades of graphite. Graphite is a brittle material with statistical variability in material properties (i.e., graphite strength). Therefore, statistical consideration of graphite strength is required to develop probabilistically based stress criteria.

Metallic design codes are termed deterministic because stresses are assigned to certain categories before being arranged as stress intensities and then compared to different allowables. The allowable stress state is determined from destructive testing with consistent results. Current computation techniques used to model the stress states in metallics have shown excellent predictive capabilities. The current state-ofthe-art modeling capabilities for graphite materials do not permit stress predictions to the same accuracy as metallic components, and therefore, using deterministic methods to predict safety margins in graphite component stress states is unreliable.

Failure criteria used in Section III of the ASME BPV code represent primarily ductile metallic materials, which follow maximum shear stress theory. Nuclear graphite is generally a heterogeneous, isotropic to slightly anisotropic, brittle material whose compressive strength is higher than its tensile strength, and its stress-strain behavior is nonlinear and dependent on hydrostatic stress. Most of the failure theories used for graphite have been generalizations of the von Mises theory. Subsection CE establishes strength limits based on maximum stress theory, because it will result in a more conservative design. Maximum stress theory states failure occurs when one of the three principal stress components at a point in a body reaches either the uniaxial tensile or uniaxial compressive strength with the weakest axis strength used. The over conservatism could result for example in core support pedestals requiring 
excessive diameters to meet code. Subsection $\mathrm{CE}$ allowed more rigorous multiaxial failure theory to be used, but this section of the code had not been developed.

An underlying axiom in all metallic deterministic ASME design codes is the use of different stress limits for primary and secondary stresses. A primary stress is produced by a mechanical load. As the mechanical load increases, the primary stress reaches a stress level where gross material yielding would occur. To mitigate this situation, a limit is placed on stress state in the material. This limit is determined from extensive destructive testing and has a factor of safety applied to ensure there is an acceptable margin. A secondary stress is produced by mechanical load or differential thermal expansion. A secondary stress indicates a strain controlled situation exists, that local yielding can be accommodated, and that the deformations are self limiting. Thus as load increases, the ratio of stress to load will decrease. Therefore, exceeding primary stress limits is judged to potentially much more damaging than exceeding secondary stress limits.

Nuclear graphite under load and undergoing irradiation produces secondary stresses which potentially could exceed primary stresses. Thus the superposition of primary and secondary stresses into one stress state will provide a more inclusive stress state to base a stress limit on. Therefore, the underlying axiom in metallic deterministic ASME design codes of primary and secondary stresses is not directly applicable to nuclear graphite under load and experiencing irradiation.

Subsection CE was developed for graphite core support structures that do not experience the neutron fluence and thermal loads as seen by graphite core components. As stated in the committee's charter, the new ASME graphite design code will include the graphite in the core. In extending the code to core components, consideration will be given to development of separate design stress limits based on safety importance and absorbed neutron fluence.

\section{PROJECT TEAM'S APPROACH}

As identified in the previous section, core supports may not see the high neutron fluence that other sections of the core would experience. This situation requires two design codes: one for unirradiated material and the other for irradiated material. The project team is working on individual codes for the irradiated and unirradiated.

The project team will recommend that a designer take into account the material properties variability within lots to lots and billet to billet when selecting representative values needed for the design. The collection of data must be made in a meaningful statistic process. The team will emphasize that it will be the owner/operator/designer's responsibility to obtain the irradiated graphite performance parameters necessary for designing the core and core supports as well as address the uncertainty in those measurements and their effects on the safety margins.

Graphite is a brittle material whose failure can be described by a Weibull distribution. Kerntechnische Ausschuss (KTA), the German ASME equivalent, has developed a graphite design code taking into account the Weibull strength distribution in the analysis of the stress state in the graphite. The team has reviewed KTA's documents and found them useful and instructive. The team will employ sections of the KTA rules in sections of the ASME code where appropriate. The team recognizes that ASTM will be forthcoming with a standard to perform measurements obtaining a Weibull strength distribution in a graphite sample population.

The NRC has published a guideline in SECY-03-0047 addressing risk informed licensing: 
Use a risk informed and performance-based approach, wherever practical, consistent with the Commission's 1995 policy statement on the "Use of Probabilistic Risk Assessment Methods in Nuclear Regulatory Activities," (60 CFR 42622);

SECY-98-144, "White Paper on Risk-Informed and Performance-Based Regulation," dated June 22, 1998; and Yellow Announcement \#019, "Commission Issuance of White Paper on Risk-Informed and Performance Based Regulation,” dated March 11, 1999.

In order to meet the future NRC requirements, a coupled probabilistic risk analysis with probabilistic stress analysis approach must be taken to develop structural design criteria that incorporates uncertainty and can be used to demonstrate how well component designs achieve their goal and meet plant risk limits. The project team will develop the procedures to ascertain irradiated graphite strength limits based on probabilistic stress analysis to statistically quantify the uncertainty in predicted mean stress. This strength limit is key to establishing an allowable stress ratio that is used plant probabilistic risk assessment analysis. The stress ratio will also incorporate the consequence of failure into the basis by assigning different ratios to core support, reflector, fuel, and control elements. The project team will be assessing the NASA CARES package to assist in determining the strength limits and ratios. The outline of the strength analysis is found in Figure 1.

The team has been reviewing the old Subsection CE language and drafting new code language. Appendix A has a working draft of the new code being written. 


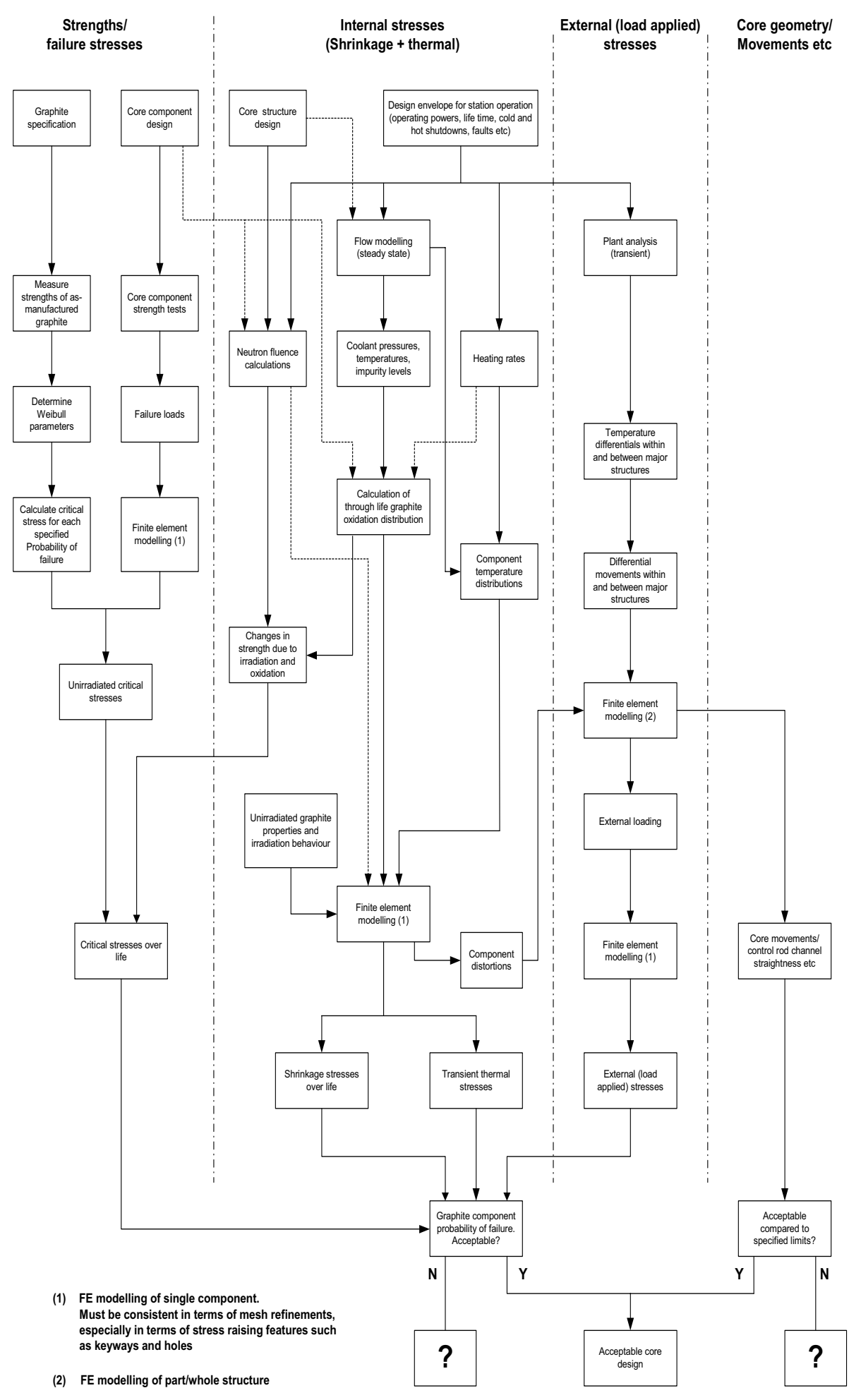

Design process flowchart

Figure 1. Design flowsheet for unirradiated and irradiated graphite. 


\section{Appendix A}

\section{Working Draft of the ASME Graphite Design Code}




\section{Position Paper: Plan for Paragraph CE-3000}

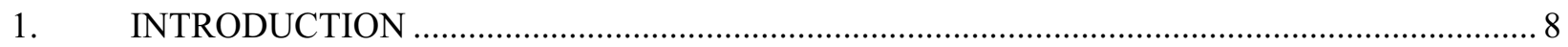

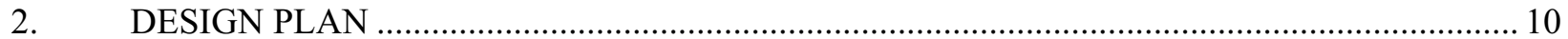

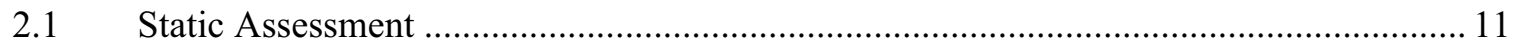

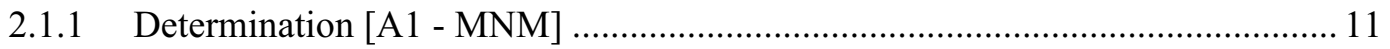

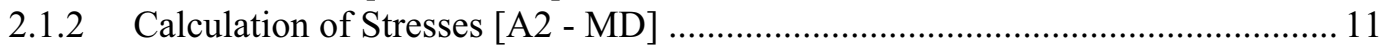

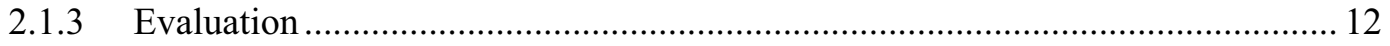

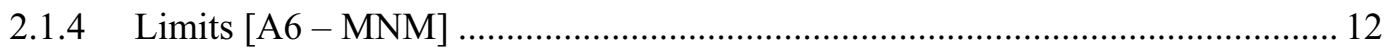

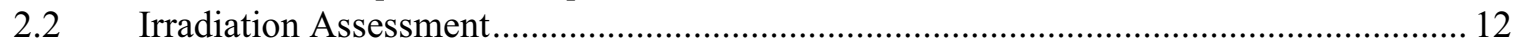

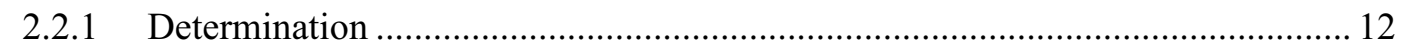

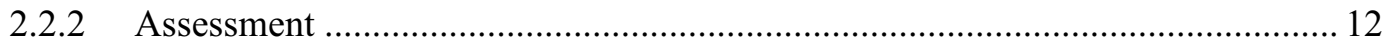

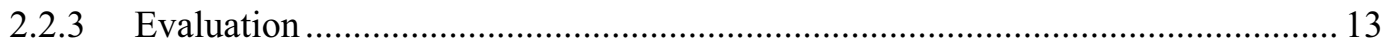

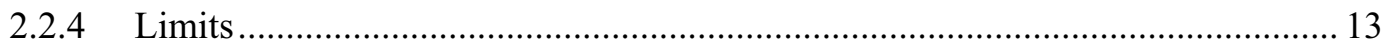

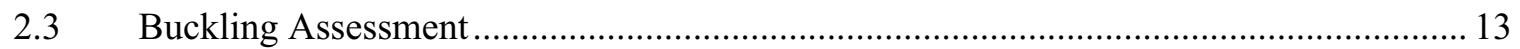

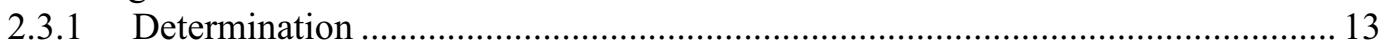

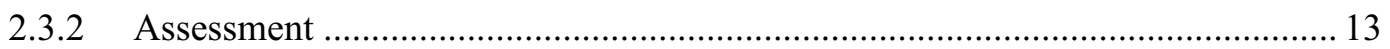

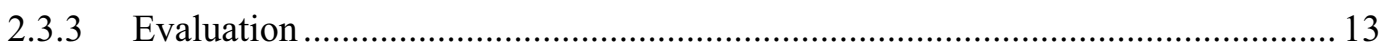

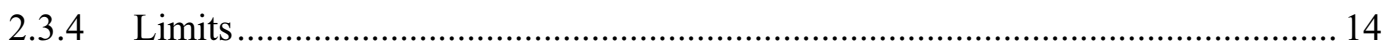

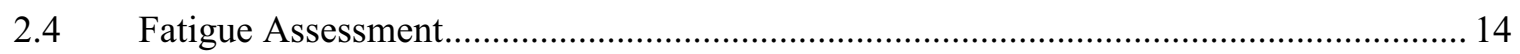

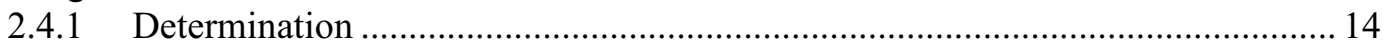

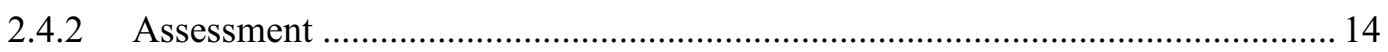

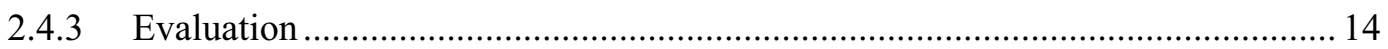

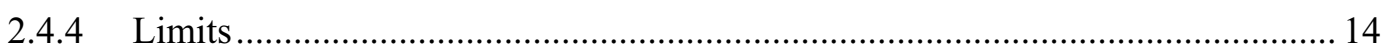

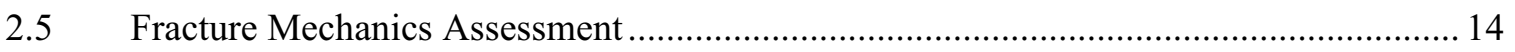

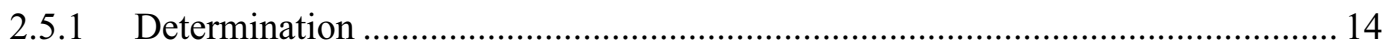

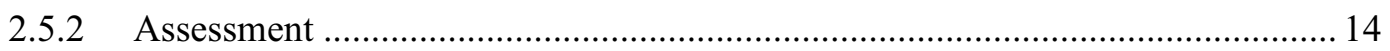

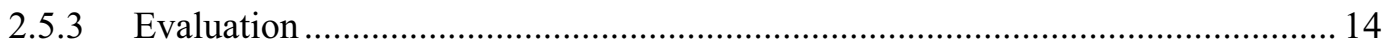

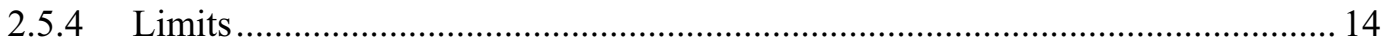




\section{INTRODUCTION}

This document aims to determine a roadmap for the design section of the ASME code for graphite core internals. This roadmap currently only covers the design of the parts for structural integrity.

The general process for designing a part is summarized in the flowchart, Figure A-1. This process comprises several separate design assessments that test the part against the required limits for the various modes of failure.

Each assessment comprises the following portions:

a. Determination of whether the effect is to be considered (Shown as the decision points in the flowchart)

b. (Stress) Assessment. The calculation of the stress field within the part (or the equivalent calculation) of the relevant failure parameter.

c. (Stress) Evaluation. Conversion of the stress parameter to the required measure of failure. This is required for comparison with the design limits that are defined.

d. Acceptance. (Comparison to limits)

This process requires input data. The determination of the input data is to be defined in other parts of the code. The input data identified are:

- $\quad$ Required limits for the loading mechanisms of the parts.

- Determination of the loading of the parts

- $\quad$ Material properties (irradiated and virgin)

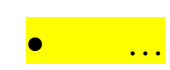

The various steps in the process are described below. 


\section{Structural Integrity Assessment}

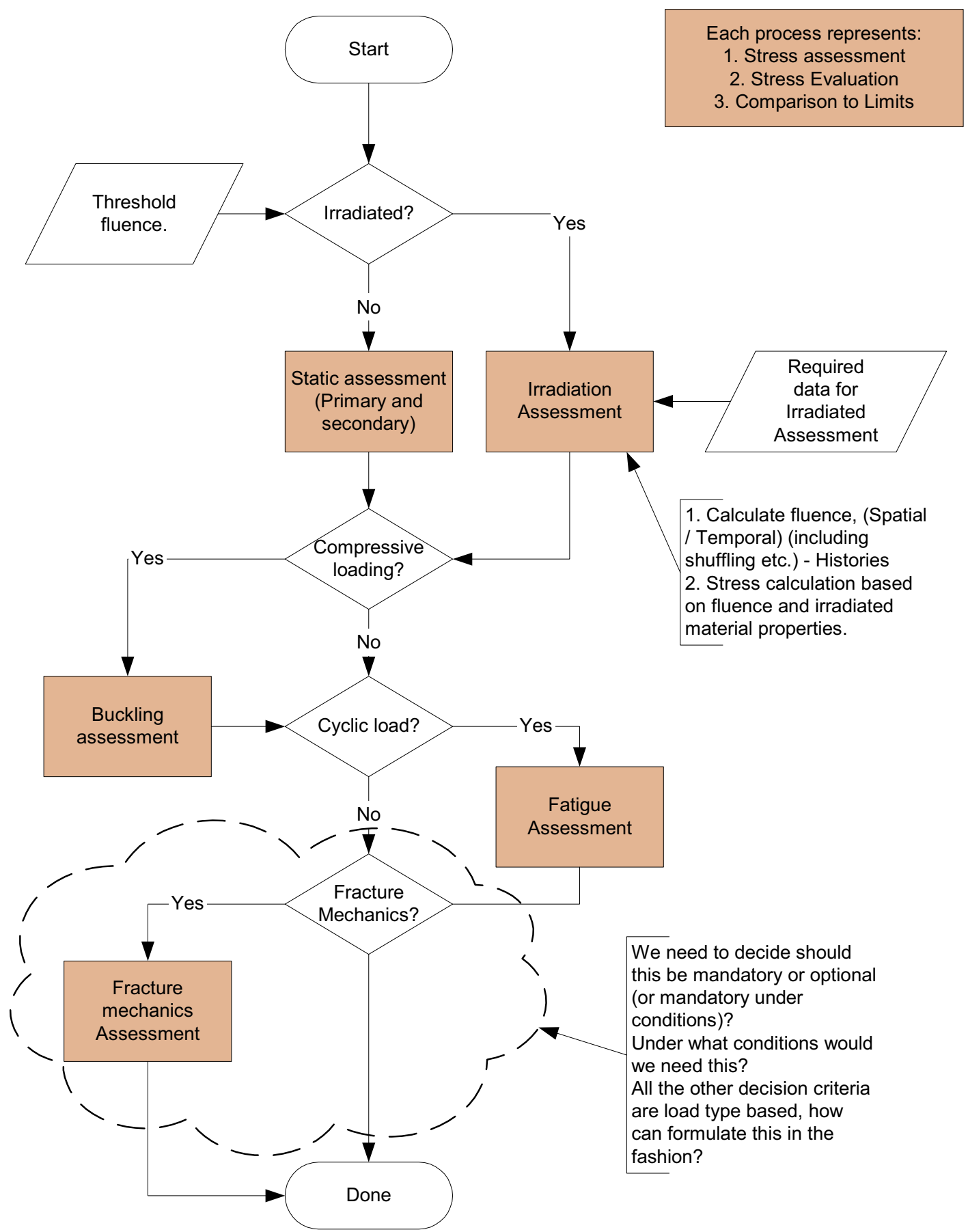

Figure A-1. Assessment flowchart. 


\section{DESIGN PLAN}

Details of the various assessments comprising the design methodology are provided in this section, a summary of these is provided in Table A-1.

All procedures are for design by analysis.

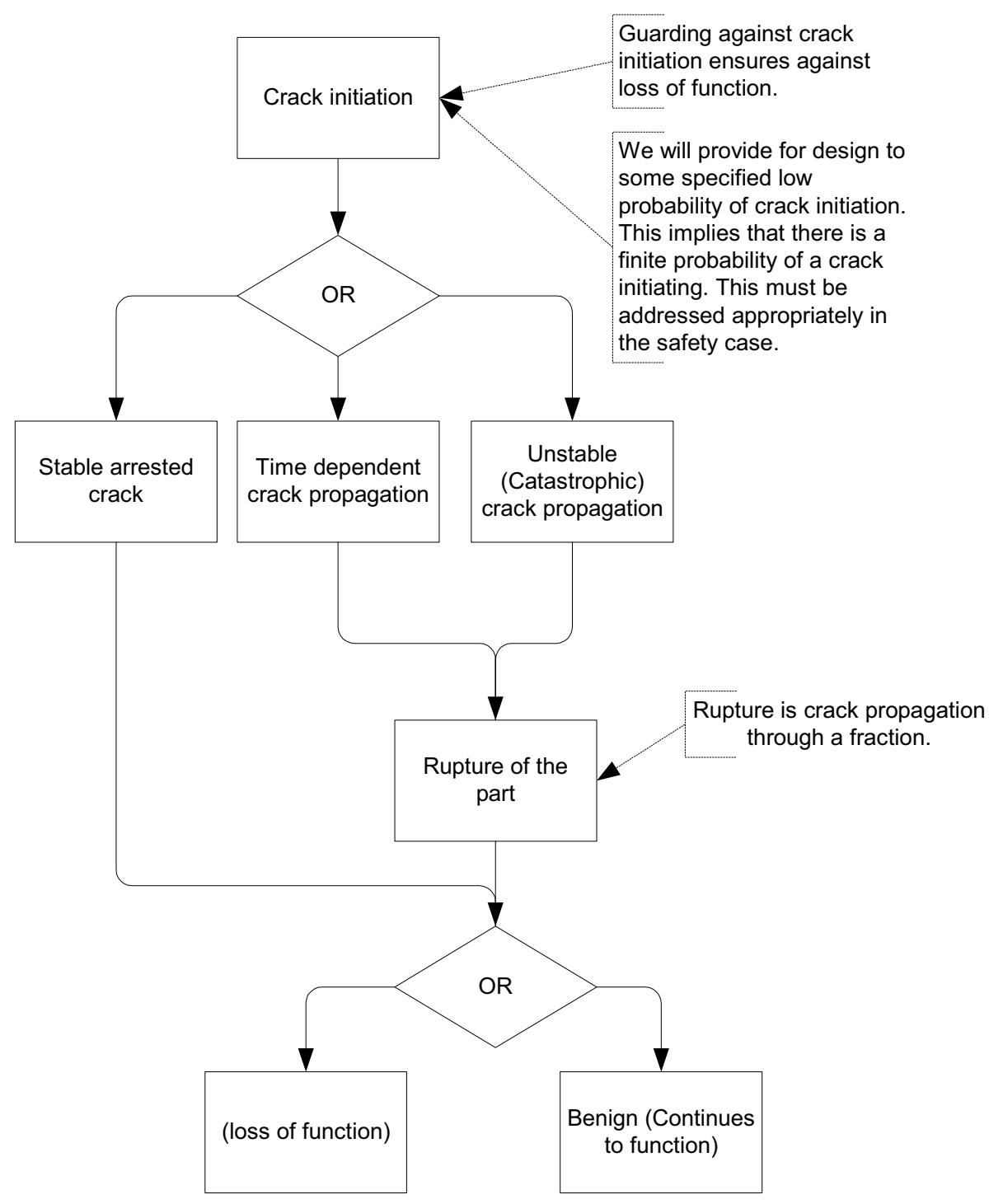




\section{$2.1 \quad$ Static Assessment}

The aim of this assessment is to ensure against brittle failure of the part when loaded or subjected to constant load for a sustained period of time.

What are we guarding against?

Failure: Failure (for static assessment) is defined as the Crack Initiation. This does not necessarily cause failure of the part to perform its functions.

Fracture:

Loss of structural integrity:

What is Crack Initiation?

Part: What is a part

The aim of this assessment is to design against crack initiation within the part when loaded at a constant level for a sustained period of time.

Designing to the specified probability of crack initiation protects against functional failure.

Robustness in terms of damage tolerance of the design is still required to tolerate the anticipated (low) number of crack initiations.

\subsubsection{Determination [A1 - MNM]}

Nonirradiated (low irradiated) parts are subject to this assessment.

This means that:

1. An irradiation limit is required. (Low) Nonirradiated: $<1 \mathrm{dpa}$

Perhaps split into three cases, non-, low, and irradiated.

\subsubsection{Calculation of Stresses [A2 - MD]}

Linear static stress analysis is acceptable.

Define

\section{Primary and Secondary Stresses}

Stress calculations must account for all simultaneous primary and secondary stresses. (Superposition of stresses is allowed as long as the spatial distribution is accounted for) features.

The stress calculation should provide an accurate prediction of the stress field around stress raising 
Inputs:

1. Loads. External and Internal. Where internal comprises temperature distributions within the part, calculation these distributions are to account for the change in thermal conductivity at doses $>0.001 \mathrm{dpa}$.

2. Material properties

3. Part geometry

\subsubsection{Evaluation}

\section{$\underline{\text { Peak Stress }}$}

[A3 - OG] Simple evaluation: The peak stress in the part is compared to a stress limit determined from the distribution of the material tensile strength values. (First Pass). This may be configured to account for membrane, membrane + bending, peak.

[A4 - NNN (MNM)] Full evaluation: Integrated failure probability using appropriate (currently volumetric ) weakest link theory, comparing an equivalent stress to the tensile strength distribution (according to KTA / Cares)

Input data:

[A5 - TB] 1. Design data are from the nonirradiated material only. (Statistical treatment (analysis) of measured data is to be defined) This data are to be confirmed using production of the material.

Will ASTM write this procedure themselves?

\subsubsection{Limits [A6 - MNM]}

Failure probability limits set appropriately for the part.

For simple evaluation, compare to the tensile stress corresponding to required FP limits as determined from the material tensile strength distribution.

\subsection{Irradiation Assessment}

The aim of this assessment is to ensure against failure of the part when subjected to irradiation during operation.

\subsubsection{Determination}

Irradiated parts are assessed as follows.

\subsubsection{Assessment}

Full nonlinear viscoelastic stress analysis based on appropriate material properties and irradiated material behavior.

The following are to be considered: 
a. Irradiation induced property changes

i. CTE Change

ii. Elastic modulus change

iii. Thermal conductivity change

b. Loading

i. Irradiation induced dimensional change (in the parallel and perpendicular directions)

ii. Irradiation conditions and history (including Flux and temperature distributions)

c. Other effects

i. $\quad$ Irradiation induced creep

ii. Wear and tear.

\subsubsection{Evaluation}

Simplified assessment not allowed. Integrated failure probability using weakest link theory (according to KTA / Cares)

\subsubsection{Limits}

Failure probability limits set appropriately for the part.

\subsection{Buckling Assessment}

The aim of this assessment is to ensure against failure of the part by buckling.

\subsubsection{Determination}

Typically: Any part loaded primarily in compression with a slenderness ratio (1/d) $>$ TBD.

\subsubsection{Assessment}

\section{Options:}

1. According to the old KTA rule, limit the compressive stress on the graphite so that buckling should not be a problem.

2. As described in CE. (Possibly including modifications as described by JAERI.)

3. Possibly a full nonlinear buckling analysis.

\subsubsection{Evaluation} value.

Compare the stress values in the component to the limits or compare the load to a critical load 
How can this be formulated in a probabilistic sense?

\subsubsection{Limits}

If probabilistic assessment, compare the required failure probabilities as defined for the cases above.

If not probabilistic, define suitable deterministic safety factors.

\subsection{Fatigue Assessment}

The aim of this assessment is to ensure against fatigue failure of the part under cyclic loading.

\subsubsection{Determination}

\subsubsection{Assessment}

\subsubsection{Evaluation}

Goodman diagrams.

\subsubsection{Limits}

\subsection{Fracture Mechanics Assessment}

To determine

1. The damage (flaw) tolerance of the part

2. 2. The post crack behavior of the part

\subsubsection{Determination}

\subsubsection{Assessment}

\subsubsection{Evaluation}

\subsubsection{Limits}

Table A-1. Summary of the methods selected for design.

\begin{tabular}{|l|l|l|l|l|}
\hline & & & & \\
\hline Loads & & & & \\
\hline Stress Assessment & & & & \\
\hline Stress evaluation & & & & \\
\hline Compare to limits & & & & \\
\hline
\end{tabular}

